\title{
EFFECT OF IMMISCIBLE LIQUID CONTAMINANTS ON P-WAVE TRANSMISSION THROUGH NATURAL AQUIFER SAMPLES
}

\author{
Jil T. Geller, Earth Sciences Div., Lawrence Berkeley National Lab., Berkeley, CA \\ Jonathan B. Ajo-Franklin, Dept. of Geophysics, Stanford University, Stanford, CA \\ Ernest L. Majer, Earth Sciences Div., Lawrence Berkeley National Lab., Berkeley, CA
}

\begin{abstract}
We performed core-scale laboratory experiments to examine the effect of non-aqueous phase liquid (NAPL) contaminants on P-wave velocity and attenuation in heterogeneous media. This work is part of a larger project to develop crosswell seismic methods for minimally invasive NAPL detection. The test site is the former DOE Pinellas Plant in Florida, which has known NAPL contamination in the surficial aquifer. Field measurements revealed a zone of anomalously high seismic attenuation, which may be due to lithology and/or contaminants (NAPL or gas phase). Intact core was obtained from the field site, and P-wave transmission was measured by the pulse-transmission technique with a $500 \mathrm{kHz}$ transducer. Two types of samples were tested: a clean fine sand from the upper portion of the surficial aquifer, and clayey-silty sand with shell fragments and phosphate nodules from the lower portion. Either NAPL trichloroethene or toluene was injected into the initially water-saturated sample. Maximum NAPL saturations ranged from 30 to $50 \%$ of the pore space. P-wave velocity varied by approximately $4 \%$ among the water-saturated samples, while velocities decreased by 5 to $9 \%$ in samples at maximum NAPL saturation compared to water-saturated conditions. The clay and silt fraction as well as the larger scatterers in the clayey-silty sands apparently caused greater P-wave attenuation compared to the clean sand. The presence of NAPLs caused a 34 to 54\% decrease in amplitudes of the first arrival. The central frequency of the transmitted energy ranged from 85 to $200 \mathrm{kHz}$, and was sensitive to both grain texture and presence of NAPL. The results are consistent with previous trends observed in homogeneous sand packs. More data will be acquired to interpret P-wave tomograms from crosswell field measurements, determine the cause of high attenuation observed in the field data and evaluate the sensitivity of seismic methods for NAPL detection.
\end{abstract}

\section{Introduction}

Non-aqueous phase liquid (NAPL) contamination of groundwater aquifers is a widespread environmental problem. In order to reduce cleanup costs and risk to the environment, accurate locations of contaminant source terms must be known. If one could confidently determine if the source volume is moving, being reduced in size due to remediation or not a threat to the environment, more cost-effective decisions regarding treatment options could be made. Currently, outside of drilling new holes, there are few if any methods to remotely detect and monitor NAPL source areas. Accurate and proven techniques to delineate and monitor the location of NAPL source terms are needed.

These needs have motivated our current project to test the ability of high-frequency crosswell seismic tomography to image NAPL contaminants. Laboratory proof-of-principle studies have demonstrated the sensitivity of seismic wave signatures to the presence of NAPL contaminants both in 1-D column (cm-scale) [4] and 3-D tank (0.5 m-scale) experiments [5], [6]. The contrast in the acoustic velocity between water and NAPLs results in slower velocities and smaller amplitudes as NAPL saturation increases in unconsolidated media. Both of these studies used homogeneous, clean sands. No such measurements have been made for natural aquifer materials. 
This work is part of a larger project to develop crosswell seismic methods for minimally invasive NAPL detection [1]. The test site is the Pinellas Science, Technology and Research (STAR) Center, a former Department of Energy (DOE) facility, in Pinellas County, Florida. In the late 1960s, construction debris and drums containing chemical wastes associated with the manufacturing of components for nuclear weapons were disposed of at the Northeast Site of the facility. The 30 foot-deep surficial aquifer is contaminated with volatile organic compouds (VOCs) and NAPL trichloroethene (TCE), toluene, methylene chloride, weathered oils and resins [7], [8]. The groundwater table is less than 10 feet below the surface; the underlying 70 foot thick clay aquitard occurs at about 30 feet depth [7]. The aquifer is composed of a heterogeneous distribution of beach-type deposits, including fine sands with variable shell content, and silty and clayey sands with shells and phosphate nodules [7].

This paper describes the laboratory investigation of core samples from the site performed for the purpose of supporting the interpretation of field data and evaluating the sensitivity of the seismic wave signature to the presence of NAPL contaminants. One particularly compelling issue is to determine the cause of an anomalously high seismic attenuation zone observed in the field data [1] from the Pinellas site. The high attenuation may be due to lithology, NAPL contaminants, residual gas phase from remediation activities, or a combination of these factors. Laboratory measurements of the relationships between P-wave transmission, immiscible fluid distributions and lithology are required for both input parameters to predictive models and determination of attenuation mechanisms.

\section{Core Acquisition and Preliminary Characterization}

\section{Core acquisition}

Our field work focused on the "South NAPL area" of the Northeast site, shown in Figure 1. The shaded areas are denoted as "approximate NAPL areas", estimated from VOC concentrations in soil boring samples [7], [8]. The NAPL distribution within these areas is irregular and discontinuous. Samples from neighboring soil borings typically had very different VOC concentrations, both above and below the concentration cutoff used to identify the presence of NAPL. NAPL was visually observed in wells M17D, RW10, RW11, M35D and 533. NAPL was withdrawn and analyzed from recovery wells RW06 and RW03. The bold line delineates the area where rotary steam drilling was tested for potential remediation [9]. Geophysical surveys and logging were performed in the "G" boreholes and site wells [1], extending from the region of presumed NAPL contamination to zones outside the area where NAPL had been detected. 


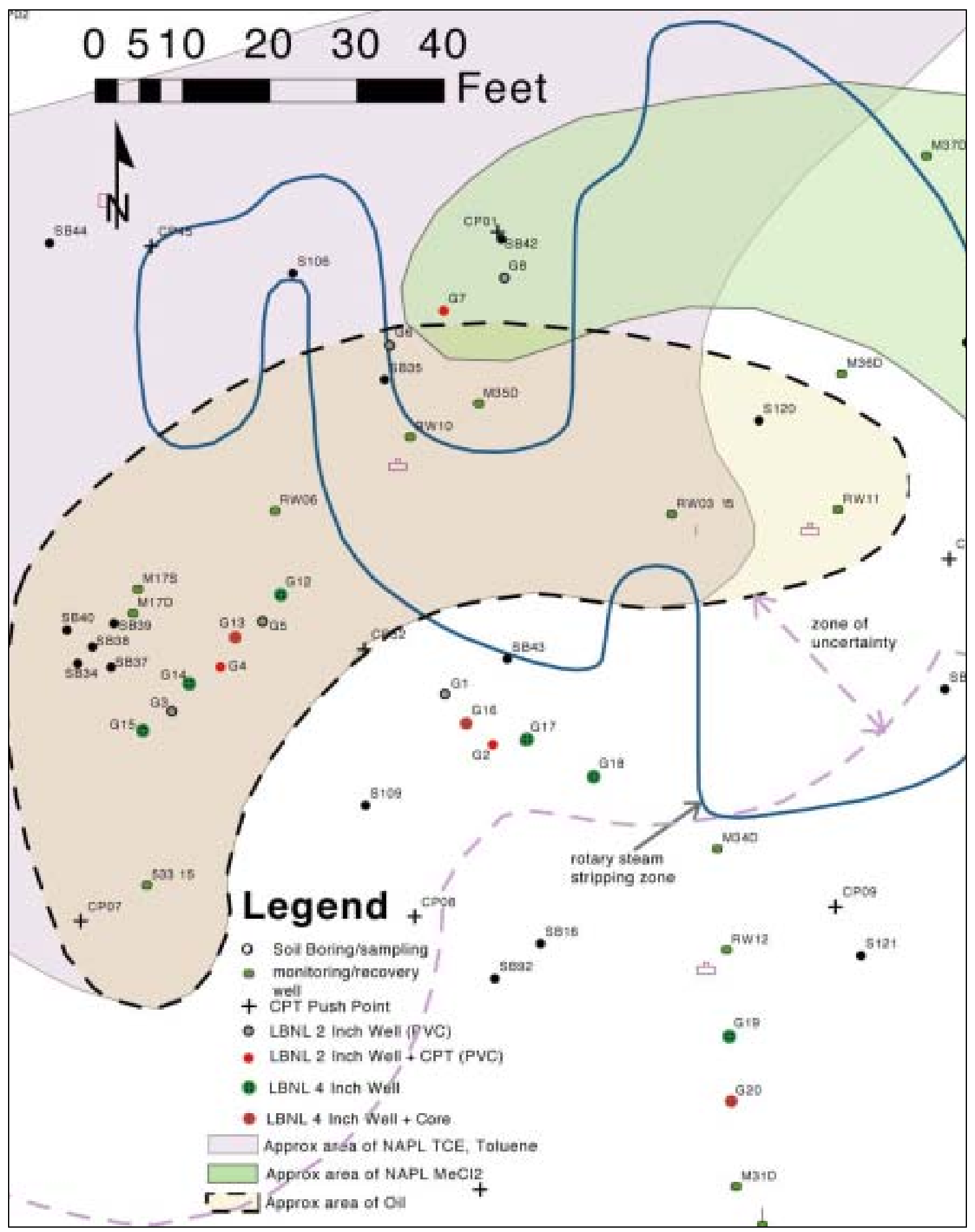

Figure 1.: Map of south NAPL area of Northeast site at Pinellas STAR Center. Locations of core sampling are indicated in dark red (G13, G16 and G20).

As part of our field test plan, one borehole in each survey line was core-drilled for laboratory testing. Drilling was performed with a rotory sonic rig, using five-foot lengths of transparent 4" diameter lexan sleeves. Initial attempts to core from approximately $1.2 \mathrm{~m}$ to $-0.4 \mathrm{~m}$ elevation $(9-14 \mathrm{ft}$ bgs $)$ failed due to the absence of cohesion in the relatively clean sands. In subsequent cores, a trap was placed in 
the bottom of the core to prevent the sand from flowing out, and core recovery was almost $100 \%$. Debris hindered core retrieval in the upper $11 \mathrm{ft}$ in some locations. Visual inspection of the core walls after core drilling showed that the cores were of good quality and relatively undisturbed. The undrained cores were sealed and packed to maintain vertical alignment during shipping to LBNL. There was evidence from inspection upon their receipt that some fluidization of the core had occurred during shipping. Some cores had a layer of free water ranging from 0.5 to $9 \mathrm{~cm}$ thick overlying the media due to compaction. Some of these cores had a layer of fines ranging from 1 to $5 \mathrm{~cm}$ thick at the top of the media due to differential settling after fluidization. Table 1 summarizes the core recovery and disturbance data.

\section{XRT characterization}

The cores were first characterized by photography of the core walls and by X-ray CT (XRT) scanning, to aid in the selection of samples for detailed analysis. The soil columns were CT scanned with a third generation Somatom HiQ modified medical scanner, using the following settings: $133 \mathrm{keV}$ beam energy, current $175 \mathrm{~mA}, 2.7 \mathrm{~s}$ exposure time, $10 \mathrm{~mm}$ slice thickness, $20 \mathrm{~mm}$ on center slice spacing, and 2.2 zoom (corresponding to a voxel size of $0.4 \mathrm{~mm}$ ). The image size was $512 \times 512$ pixels and 12 bits deep. The depth corresponds to a range of attenuation 0-4095 Houndsfield Units (HU), with air at $0 \mathrm{HU}$, water at $1000 \mathrm{HU}$ and soil in the range 2000-2500 $\mathrm{HU}$.

To prevent sample movement during horizontal alignment for XRT, the cores were drained of free pore-liquid to provide apparent cohesion for the unconsolidated media and the tops of the tubes were cut to remove the headspace. Draining was done by siphoning the top layer of free water and punching holes in the bottom core cap and collecting water that drained out the bottom. The electrical conductivity and ionic composition of the drained pore water were measured.

Table 1. Core recovery data

\begin{tabular}{|l|c|c|c|c|c|c|}
\hline $\begin{array}{c}\text { Core name } \\
\text { borehole } \\
\& \text { core } \\
\text { section \#) }\end{array}$ & $\begin{array}{c}\text { core } \\
\text { recovery } \\
(\%)\end{array}$ & $\begin{array}{c}\text { estimated } \\
\text { compaction of } \\
\text { core }(1)(\%)\end{array}$ & $\begin{array}{c}\text { settled fines } \\
\text { thickness } \\
(\mathrm{cm})\end{array}$ & $\begin{array}{c}\text { free water } \\
\text { layer } \\
\text { thickness } \\
(\mathrm{cm})\end{array}$ & $\begin{array}{c}\text { vol water } \\
\text { siphoned } \\
\text { from top } \\
(\mathrm{mL})\end{array}$ & $\begin{array}{c}\text { vol water } \\
\text { drained from } \\
\text { bottom } \\
(\mathrm{mL})\end{array}$ \\
\hline G13 \# 1 & 95 & 5.2 & none & 6.0 & 425 & 115 \\
\hline G13 \# 2 & 96 & 5.2 & none & 4.0 & 245 & 645 \\
\hline G13 \# 3 & 95 & 8.5 & $0.5-3$ & 6.0 & $(2)$ & 100 \\
\hline G13 \# 4 & 100 & 4.6 & 4 & 5.0 & 400 & 64 \\
\hline G16 \# 1 & 100 & 7.2 & none & 9.0 & 575 & 180 \\
\hline G16 \# 2 & 48 & 7.9 & none & none & n.a. & 81 \\
\hline G16 \# 3 & 80 & 7.2 & none & none & n.a. & 510 \\
\hline G16 \# 4 & 100 & 5.6 & 0.5 & 6.0 & $(2)$ & 30 \\
\hline G16 \# 5 & 100 & 5.6 & $0.5-0.1$ & 4.5 & $(2)$ & $(2)$ \\
\hline G17 \# 1 & 100 & 1.0 & none & none & n.a. & 122 \\
\hline G20 \# 1 & 100 & 5.2 & none & none & n.a. & $(2)$ \\
\hline G20 \# 2 & 100 & 2.0 & 3 & 0.5 & 120 & 35 \\
\hline G20 \# 3 & 100 & 5.2 & 4 & 6.0 & 340 & 45 \\
\hline G20 \# 4 & 100 & 5.9 & 3 & 7.0 & 180 & 20 \\
\hline $\begin{array}{l}\text { Notes: } \\
\text { (1) calculated from length of headspace in five-foot core section after shipping }\end{array}$ \\
(2) not measured
\end{tabular}


Figure 2 shows the photographs and XRTs of cores obtained from boreholes G13, G16, G17, and G20, aligned according to their elevations, and the CPT-derived lithology from borehole G04 (near G13). Gaps in core images from boreholes G16 and G20 indicate where core was lost during drilling. Borehole G17 was core-drilled over the depth that was lost in G16. The photographs show distinct color changes with elevation, which are consistent in each borehole. In the upper portion of the surficial aquifer, a color change from light brown to dark brown occurs at about $2.4 \mathrm{~m}$ elevation in G16 and G20. Some streaking along the walls due to fluidization can be seen. From approximately -0.5 to $-1.75 \mathrm{~m}$ the color of the core changes from medium gray to dark gray, and the cores from the lower part of the surficial aquifer are light gray. The XRTs also show that density values change consistently with elevation among all the boreholes. The density values are sensitive to the density contrast of the fluid phases (air versus water) and of the different solid phase constituents. Cores from the middle of the surficial aquifer have lower densities in the top half of the core, due to increased water drainage of the top half before imaging. The cores from the lower part of the surficial aquifer have the highest density of all, with significant fine-scale variability that is not visible in the photographs. The CPT lithology also shows increased variability in structure in the lower part of the surficial aquifer. The G20 core from this zone has higher density than G13 and G16. 


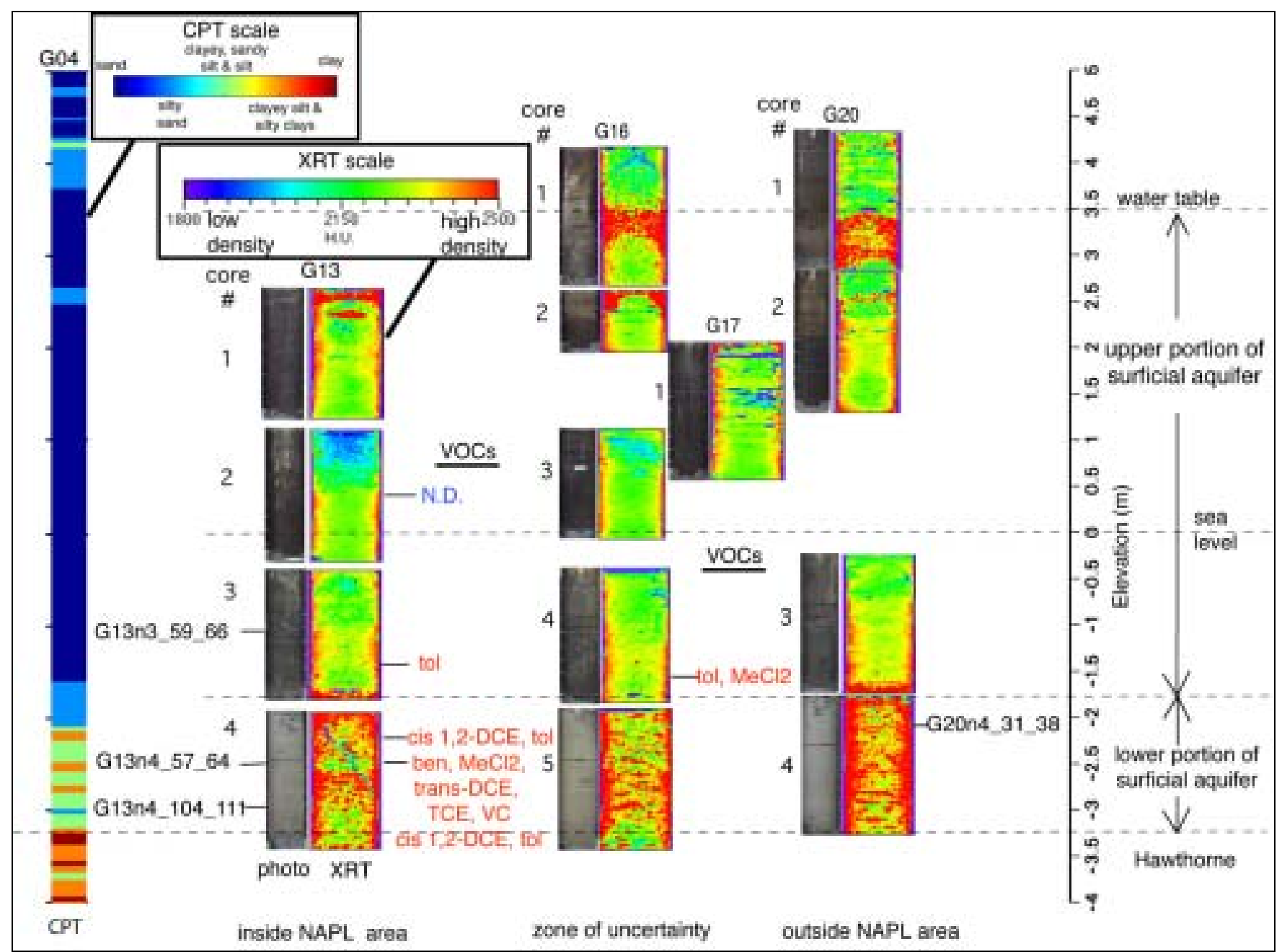

Figure 2.: Photographic and X-ray tomographic images of core acquired from the Northeast site, shown with the CPT-derived lithology measured in borehole G04, which is near borehole G13. VOCs listed in red were detected in samples from the indicated elevations, N.D.=no detect. Ben=benzene, $\mathrm{MeCl} 2=$ methene chloride, $\mathrm{DCE}=$ di-ethene chloride, $\mathrm{VC}=$ vinyl chloride, tol=toluene. Elevations are referenced to National Geodetic Vertical Datum of 1929 and are based on closed level loops which include “St. Pete N.W. Base C”, Pinellas County map number 1093, Elevation 5.354 m.

\section{VOC concentrations}

As cores were cut (described in following section), several soil samples were taken from the G13 core and one from the G16 core for VOC analysis by purge-and-trap gas chromotography (EPA method 8260B). The results qualitatively indicate the presence of contaminants, but were not considered quantitative because measures were not taken to preserve chemical integrity during core acquisition and handling. Furthermore, only five grams of sample were used for analysis, which was not necessarily representative of bulk concentrations. The number of contaminant species and their concentrations increased at the lower elevations. The maximum measured concentration was 3,000 $\mu$ g-toluene/kg-soil at the lowest sample point in G13; this is less than the concentration of $15,000 \mu \mathrm{g} / \mathrm{kg}$ which has been used to indicate the presence of NAPL [7]. 


\section{Detailed Sample Characterization}

\section{Methods}

Figure 3 shows the test cell schematic to measure P-wave transmission by pulse-transmission through soil samples of varying NAPL/water saturation. The endcaps have a $7.25 \mathrm{~cm}$ outside diameter and are made of compression molded polyphenylene sulfide, also known as PPS or ryton, which is resistant to organic solvents. A well in each endcap holds the transducer and isolates it from direct contact with the sample. The transducers are $0.5 \mathrm{MHz}$ P-wave contact transducers with a $2.54 \mathrm{~cm}$ diameter element (Part No. V101, Panametrics, Waltham, MA). Each endcap has two fluid ports that run through the annulus over the length of the endcap. The face of the endcap annulus has flow distribution grooves. A 400-mesh stainless steel screen (0.001" wire diameter) covers the endcap face for further flow distribution. A porous ceramic plate with a 5 bar $(500 \mathrm{kPa})$ entry pressure is placed on the endcap-face on the down-gradient side of the sample, such that only water flows out of the sample as NAPL is injected. The sample is held by a flexible-wall jacket, either teflon heat-shrink tube for pure liquids and coarse-grained samples, or a custom-manufactured viton elastomer jacket for finer-grained samples. Pure viton is the only elastomer we found to be compatible with TCE.

Axial and confining loads are maintained by syringe pumps (model 500D, Isco Inc., Lincoln, $\mathrm{NE}$ ) that operate in constant-pressure mode. Liquid volume changes in the confining liquid are monitored from the pump display. To represent shallow subsurface conditions, the confining pressure is set to 0.6 times the axial pressure. Changes in sample length are monitored by manually recording the reading from a deformation gage attached to the load frame and resting on the top of the upper endcap. NAPL is injected into the water-saturated sample at a constant injection pressure, using a transfer cylinder that is driven by the liquid delivery syringe pump.

The transducer is driven by a voltage pulse generator (IRCO, model M1k-20) set to produce an approximate square wave of about $0.8 \mu$ s width and 400 volts amplitude. One hundred received waveforms are stacked and saved on a digital oscilloscope (Lecroy 9310A, $400 \mathrm{MHz}$ ). 


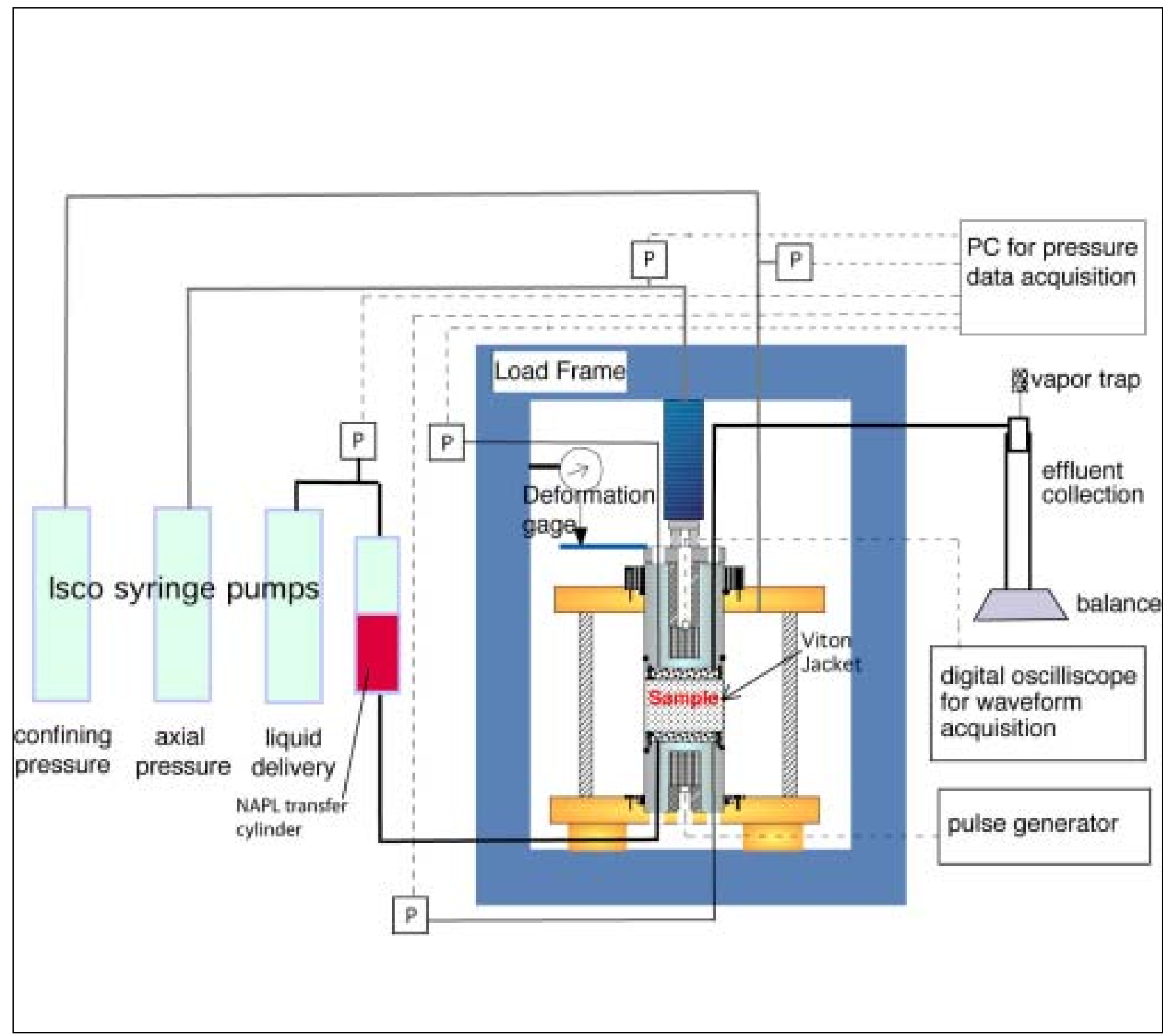

Figure 3.: Triaxial test cell schematic for saturating core samples and measuring change in P-wave velocity with NAPL saturation

Sections of 7-cm length were taken from the vertically-mounted core by cutting the core wall with a grinding tool, and then slicing through the core cross-section with a sharpened, thin stainless steel plate. A thin-walled $6.93 \mathrm{~cm}$ ID tube was pressed into the core section to retrieve a subcore over the entire 7-cm length and then frozen. The frozen subcore was pushed into the viton jacket, placed into the triaxial cell and loaded axially and with confining water. P-wave transmission and sample settling indicated when the sample was no longer frozen.

Pore water for sample saturation was prepared by equilibrating deionized/distilled water with core material from the annulus surrounding the subcore. This water was deaired by vacuum before introducing it into the sample. Pore pressure was incrementally increased to a maximum of $350 \mathrm{kPa}$ while adjusting the axial and confining pressures to maintain constant effective-stress conditions of 380 $\mathrm{kPa}$. The first arrival time of the P-wave decreased, and the amplitude increased as water saturation increased. The sample was considered fully water-saturated when the P-wave signature no longer 
changed with additional water flow. Hydraulic conductivity of a water-saturated sample without a ceramic endplate was calculated from the measured flow rate and differential pressure across the sample at different flow injection pressures.

The NAPL injected into the water-saturated samples was dyed with $125 \mathrm{mg} / \mathrm{L}$ oil-red-O dye (Sigma Aldrich) to visually differentiate it from water. Effluent water was directed to a $100 \mathrm{~mL}$ graduated cylinder sealed with a stopper connected to a granulated carbon trap to prevent the escape of organic vapors into the room. To achieve stable displacement conditions, toluene (less dense than water) was injected from the top of the sample, and TCE (denser than water) is injected from the bottom of the sample at a constant pressure. The flow rate of NAPL was measured from both the pump indicator, and the mass of effluent collected over time. The injection pressure was increased incrementally when the flow rate decreased to near zero. P-wave transmission was monitored and waveforms are recorded with incremental volume of displaced water. Effective stresses were set higher than in-situ conditions in order to maintain the seal of the viton jacket over the endcaps. The test ended when NAPL injection pressures reached 280 to $350 \mathrm{kPa}$, which was well below the $500 \mathrm{kPa}$ entry pressure of the ceramic plate.

Following the test, the sample was oven-dried at $105^{\circ} \mathrm{C}$ to determine the dry mass of solid. Porosity was calculated from the dry mass of the solid, the measured specific gravity of the solid and the sample dimensions. Porosity measurements have an uncertainty associated with the value of the sample diameter because of the flexible jacket. Sample diameter was estimated as the average of the inside diameter of the sample subcoring tool $(69.8 \mathrm{~mm})$ and the outside diameter of the endcap $(72.5 \mathrm{~mm})$. NAPL saturation was calculated from the ratio of the volume of NAPL in the sample (equal to the volume of water collected in the effluent) to the sample pore volume (calculated from porosity). The dried sample was homogenized and sieved to remove grains greater than $2 \mathrm{~mm}$ in size, then approximately $100 \mathrm{~g}$ of the remaining sample was taken for sedimentation analysis to determine the fraction of clay, silt and sand, and size distribution of the sand fraction, using the procedures described in [2].

\section{Results and Analysis}

Acoustic velocities for the fluids of interest at the Pinellas site are shown in Table 2. NAPLs and air have significant velocity contrasts with water. The fraction of energy of an incident P-wave reflected by a flat phase interface varies for the different NAPL-water pairs. The table shows that the impedance contrast between water-saturated sand and PPS is lower than for any other sand-solid pairs, making PPS a good choice for endcap material. 
Table 2. Physical properties of various fluids and solids.

\begin{tabular}{|c|c|c|c|c|c|c|}
\hline & $\begin{array}{c}\text { acoustic } \\
\text { velocity } \\
V_{P} \\
(\mathrm{~km} / \mathrm{s}) \\
\end{array}$ & $\begin{array}{c}\text { density } \\
\rho(\mathrm{kg} / \mathrm{m} 3)\end{array}$ & $\begin{array}{l}\text { viscosity } \\
\text { (cP) }\end{array}$ & $\begin{array}{c}\text { acoustic } \\
\text { impedance } \rho V_{p} \\
\left(\mathrm{~kg} / \mathrm{m}^{2}-\mathrm{s}\right)\end{array}$ & $\begin{array}{c}\text { bulk modulus } \\
V_{p}^{2} \rho(\mathrm{MPa})\end{array}$ & $\begin{array}{c}\text { reflection } \\
\text { coefficient } R\end{array}$ \\
\hline Fluids & & & & & & $\begin{array}{c}\text { from water to } \\
\text { NAPL }\end{array}$ \\
\hline Air & $0.344^{(2)}$ & 1.293 & 0.018 & $4.447 \mathrm{E}+02$ & 0.153 & $9.99 \mathrm{E}-01$ \\
\hline water & $1.47^{(2)}$ & 997 & 1 & $1.493 \mathrm{E}+06$ & 2234 & -- \\
\hline toluene & $1.321^{(3)}$ & 870 & 0.552 & $1.149 \mathrm{E}+06$ & 1518 & $1.30 \mathrm{E}-01$ \\
\hline RTV & $1.000^{(3)}$ & 1080 & 10,000 & $1.080 \mathrm{E}+06$ & 1080 & $1.60 \mathrm{E}-01$ \\
\hline methylene chloride & $1.080^{(3)}$ & 1335 & 0.449 & $1.442 \mathrm{E}+06$ & 1557 & $1.74 \mathrm{E}-02$ \\
\hline tetrachloroethene & $1.080^{(3)}$ & 1631 & 1.932 & $1.761 \mathrm{E}+06$ & 1902 & $-8.27 \mathrm{E}-02$ \\
\hline Carbon tetrachloride & $0.926^{(3)}$ & 1584 & 0.965 & $1.467 \mathrm{E}+06$ & 1358 & $8.69 \mathrm{E}-03$ \\
\hline TCE & $1.05^{(3)}$ & 1480 & 0.566 & $1.554 \mathrm{E}+06$ & 1632 & $-2.02 \mathrm{E}-02$ \\
\hline Solids & & & & & & $\begin{array}{c}\text { from water- } \\
\text { saturated sand to } \\
\text { solid }\end{array}$ \\
\hline $\begin{array}{l}\text { water sat'd lonestar } \\
2 / 12 \text { sand }\end{array}$ & $1.864^{(3)}$ & 2010 & -- & $3.747 \mathrm{E}+06$ & 6984 & -- \\
\hline lexan & $2.238^{(3)}$ & 1180 & -- & $2.641 \mathrm{E}+06$ & 5910 & $1.73 \mathrm{E}-01$ \\
\hline pps & $2.519^{(3)}$ & 1329 & -- & $3.347 \mathrm{E}+06$ & 8431 & $5.64 \mathrm{E}-02$ \\
\hline teflon & $1.345^{(3)}$ & 2187 & -- & $2.941 \mathrm{E}+06$ & 3956 & $1.20 \mathrm{E}-01$ \\
\hline aluminum & $6.420^{(2)}$ & 2700 & -- & $1.733 \mathrm{E}+07$ & 111284 & $-6.45 \mathrm{E}-01$ \\
\hline
\end{tabular}

The results of the core tests are summarized in Table 3. The samples from the upper portion of the surficial aquifer (G13n3 core) are composed of clean sands, and have lower porosities than the lower surficial aquifer samples (the G13n4 and G20n4 cores); the latter have significantly higher silt and clay contents. The hydraulic conductivity of the upper surficial aquifer is two-and-a-half orders of magnitude greater than that of the lower surficial aquifer. The sand fraction in the G13n4 core has a larger percentage of medium and coarse sand than the sand fraction in the G20n4 core.

Figure 4 shows the waveforms for the four samples, comparing the water-saturated case, with the point of maximum NAPL saturation. Several qualitative observations can be made from these plots. The samples with NAPL have both delayed first arrivals and smaller amplitudes than the water-saturated samples. The amplitude of the water-saturated clean-sand sample is greater than the clayey-silty sand samples. Finally, comparing the clayey-silty sand samples, the waveform through the sample from G20 has a larger amplitude than through the samples from G13. 
Table 3. Summary of core sample characterization

\begin{tabular}{|c|c|c|c|c|c|c|c|c|c|c|}
\hline Sample (1) & $\begin{array}{l}\text { elev. } \\
\text { (m) }\end{array}$ & $\begin{array}{l}\text { Porosity } \\
\text { (5) }\end{array}$ & $\begin{array}{l}\text { sand:silt: } \\
\text { clay }\end{array}$ & $\begin{array}{c}\text { sand } \\
\text { (fine:medium: } \\
\text { coarse) (4) }\end{array}$ & $\begin{array}{c}\text { Hydraulic } \\
\text { Conductivity } \\
(\mathrm{cm} / \mathrm{s})\end{array}$ & $\begin{array}{c}\text { Vp, water } \\
\text { sat'd } \\
(\mathrm{mm} / \mu \mathrm{s})\end{array}$ & NAPL & $\begin{array}{l}\text { Max } \\
S_{\mathrm{NAPL}}\end{array}$ & $\begin{array}{c}\text { (3) } \Delta \mathrm{Vp} \\
(\%)\end{array}$ & $\begin{array}{l}\text { (3) } \Delta \mathrm{A} \\
(\%)\end{array}$ \\
\hline G13n3_52_59 & -0.9 & 0.42 & $\begin{array}{c}\text { not } \\
\text { measured }\end{array}$ & -- & $5.2 \mathrm{E}-2$ & 1.78 & -- & -- & -- & -- \\
\hline G13n3_59_66 & -1.0 & 0.37 & 95:1:4 & $97: 3: 0$ & -- & 1.78 & TCE & 0.44 & 8.62 & 40.77 \\
\hline G13n4_57_64 & -2.5 & 0.45 & $60: 26: 14$ & $74: 7: 19$ & -- & 1.73 & Toluene & 0.42 & 5.48 & 44.07 \\
\hline G13n4_96_103 & -2.9 & 0.46 & $59: 28: 13$ & $62: 11: 27$ & $1.1 \mathrm{E}-4$ & 1.71 & -- & -- & -- & -- \\
\hline $\begin{array}{l}\text { G13n4_104_111 } \\
\text { (2) }\end{array}$ & -3.0 & 0.46 & $67: 21: 17$ & $68: 10: 22$ & -- & 1.74 & TCE & 0.30 & 5.42 & 33.93 \\
\hline G20n4_20_28 & -2.0 & 0.46 & $57: 30: 13$ & $86: 5: 9$ & -- & 1.77 & -- & -- & -- & -- \\
\hline G20n4_31_38 & -2.1 & 0.44 & $53: 34: 13$ & $84: 5: 11$ & -- & 1.76 & Toluene & 0.50 & 8.15 & 53.38 \\
\hline
\end{tabular}

$\mathrm{Vp}=\mathrm{P}$-wave velocity; $\mathrm{S}_{\mathrm{NAPL}}=\mathrm{NAPL}$ saturation; $\mathrm{A}=$ Amplitude of first arrival (peak to trough).

Notes:

(1) Samples are labeled by borehole \#, core \#, distance from top of core to sample top in cm, distance from top of core to sample bottom in $\mathrm{cm}$.

(2) Sample had several large (up to $5 \mathrm{~cm}$ long) shell fragments.

(3) Change in value from water-saturated to maximum NAPL saturation.

(4) Using ASTM (unified) classification according to particle size: fine 80-500 $\mu \mathrm{m}$; medium 500-2000 $\mu \mathrm{m}$; coarse 2000-5000 $\mu \mathrm{m}[3]$

(5) Error in measurement is estimated to be $\sim 0.02$.

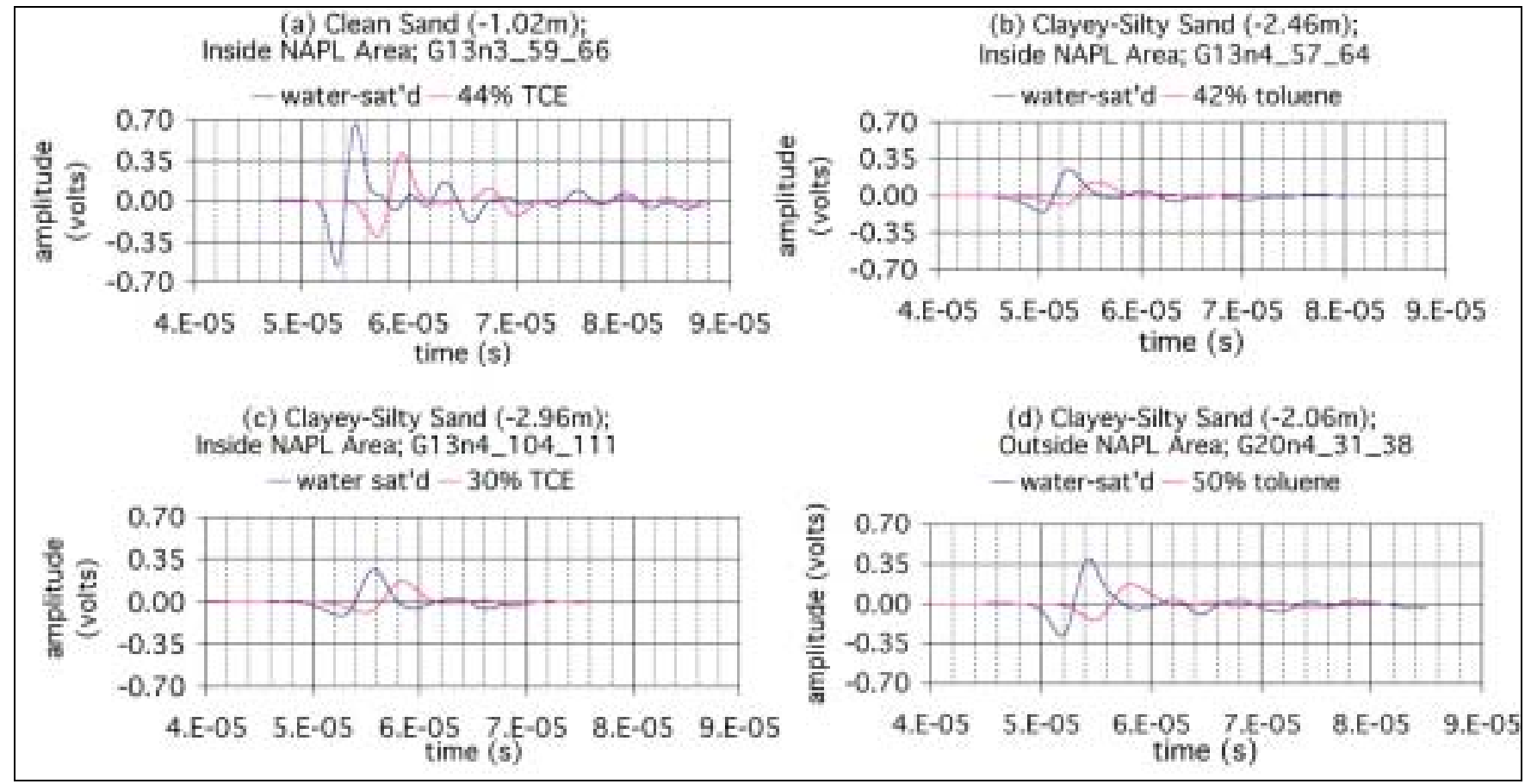

Figure 4.: P-waves through core samples fully water-saturated, and for maximum NAPL saturation.

P-wave velocity was calculated from the measured sample length and the arrival time of the first troughto-peak zero crossover. The crossover point was used because it was difficult to consistently pick the first break from the baseline. A separate measurement of P-wave transmission through the endcaps and water-saturated ceramic endplate was made to determine the time constant. Figure 5 shows the change 
in P-wave velocity and amplitude through each sample as a function of NAPL saturation, along with effective axial stress and pore pressure. 


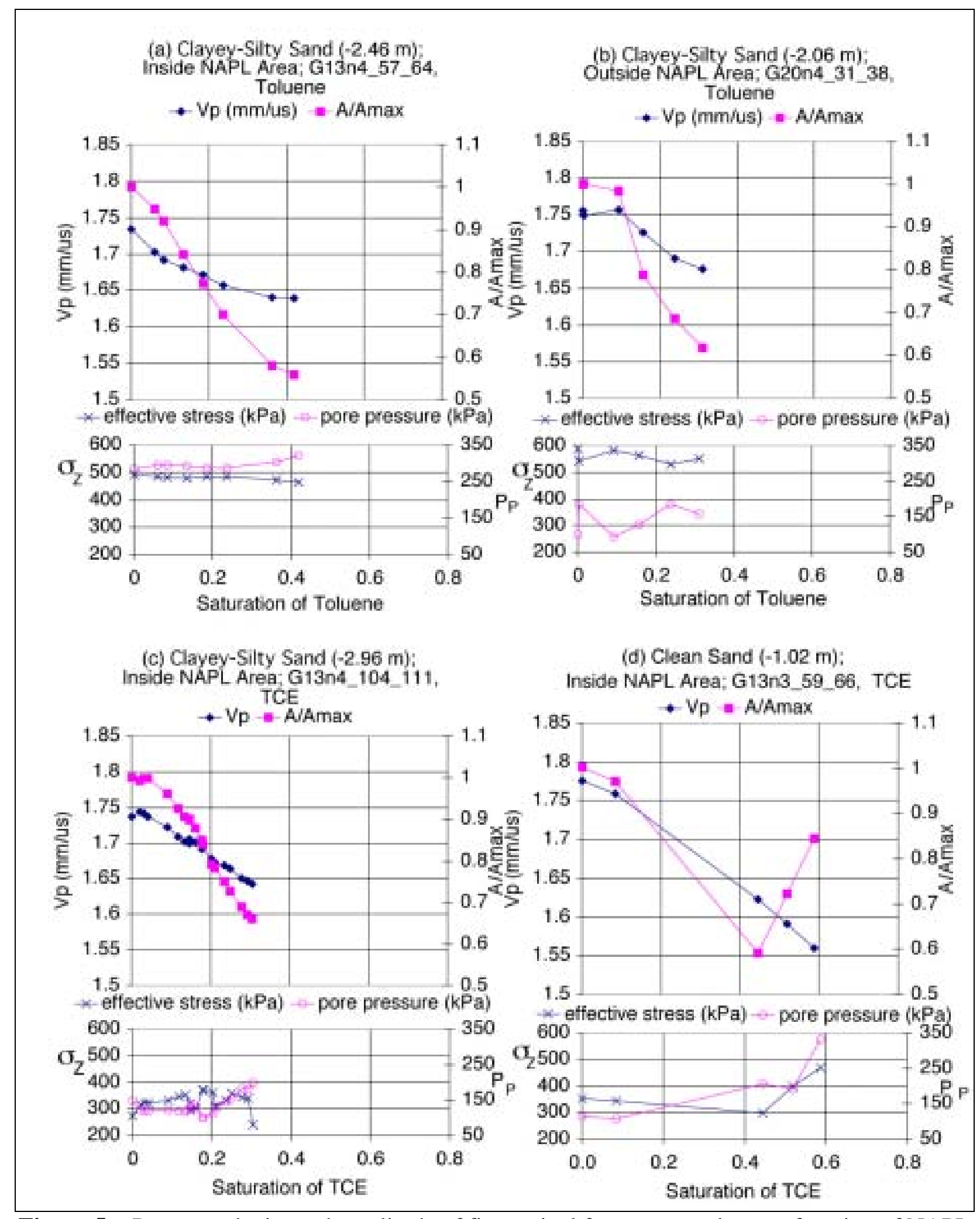

Figure 5.: P-wave velocity and amplitude of first arrival for core samples as a function of NAPL saturation. Elevation of top of sample is noted in parenthesis. $\mathrm{Vp}=\mathrm{P}$-wave velocity; $\sigma_{\mathrm{Z}}=$ effective axial stress; $\mathrm{P}_{\mathrm{P}}=$ pore pressure. 
Maximum NAPL saturations of 50\% were attained for pore-pressures up to $350 \mathrm{kPa}$. This pore pressure is equivalent to a 30 meter height of water column, which is higher than samples at 10 meters depth would have experienced in situ. This suggests that NAPL saturations at these depths would be less than 50\%, and penetration to these depths would occur either through cracks, or through more permeable flow paths than those present in the core samples. At the highest NAPL saturations, P-wave velocities decreased 5\% to almost $9 \%$, and amplitudes decreased $35-55 \%$, relative to values through the water-saturated samples (see Table 3). The velocity change is within the $10-12 \%$ range of $\mathrm{P}$-wave velocities measured in the field [1].

In a given test, effective stress was maintained at a fairly constant value, but not necessarily between tests. In the clean sand sample (Figure 5d, G13n3_59_66), amplitudes did increase in response to effective stress. Comparing G13n4_57_64 and G13n4_104_111 in Figures 5a and c, respectively, the higher effective stress in G13n4_57_64 did not affect the water-saturated velocity, nor the amplitude trend, however the velocity trends of the two samples differ. The velocity-saturation relationship for G13_n4_104_111 is more linear, and has a greater slope than the trend for G13n4_57_64. The presence of large shell fragments in G13n4_104_111 (noted in Table 3) may have affected the distribution of NAPL in the sample. More data is needed to determine if the velocity trend is sensitive to the difference in NAPL properties (TCE verses toluene, noted in Table 1), the geometry of NAPL distribution or effective stress.

To further evaluate P-wave attenuation in the core samples, amplitude spectra were computed by fast Fourier transform of the first arriving pulse. The tail of the pulse was tapered to the baseline by multiplying the descending end of the pulse, beginning at two-thirds the peak amplitude, by a cosine function. In Figure 6, the amplitude spectra for the water-saturated samples are compared with a water standard of the same length. The spectra are similar for each type of media (i.e. clean sand vs. clayeysilty sands.) The central frequency of the water standard is $350 \mathrm{kHz}$, about $200 \mathrm{kHz}$ for the clean sands, and about $100 \mathrm{kHz}$ for the clayey-silty sands. The G20n4 sample has a central frequency of about 10 to $20 \mathrm{kHz}$ higher than the G13n4 samples, and higher amplitude. 


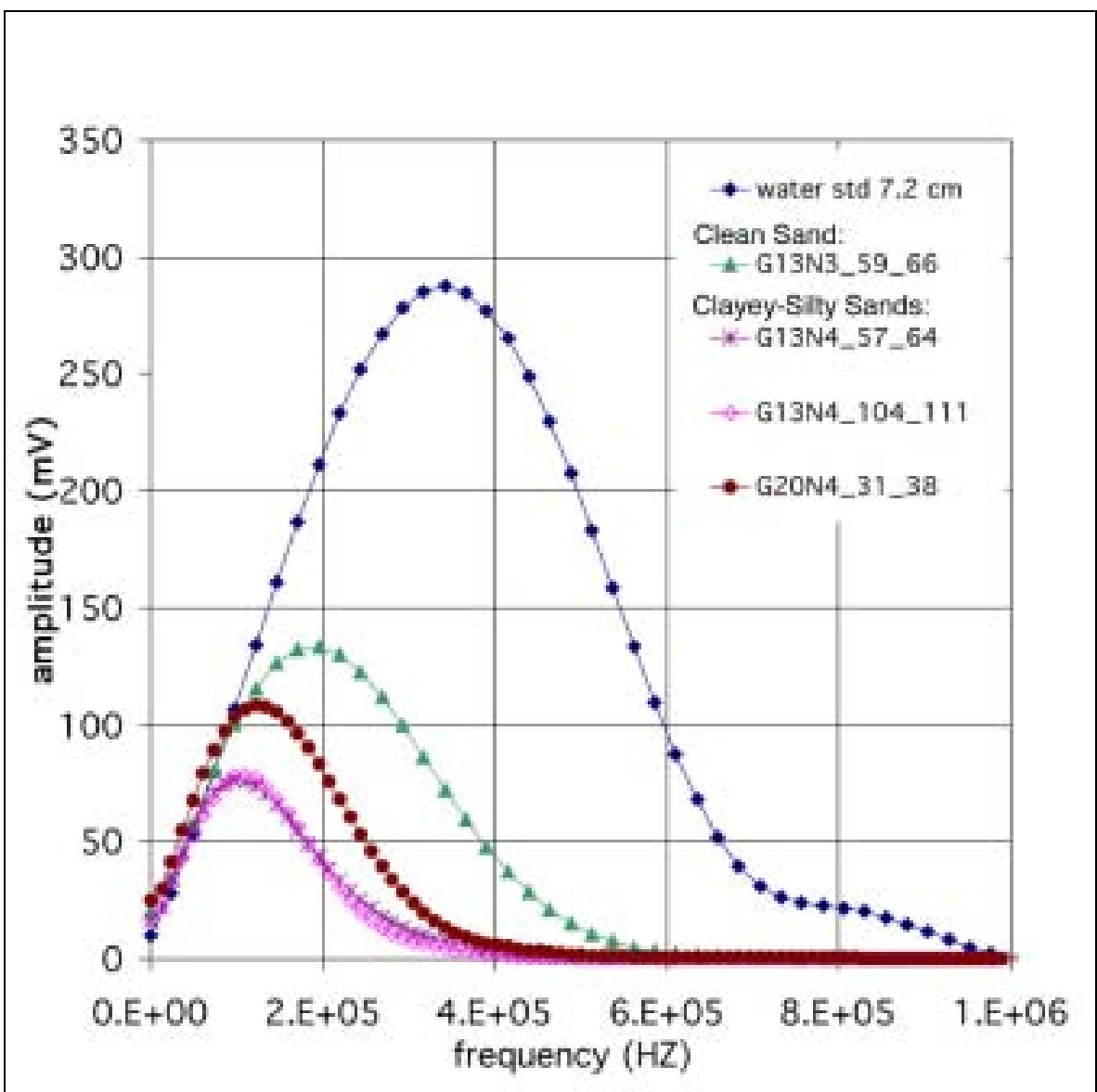

Figure 6.: Amplitude spectra for water and water-saturated samples of same length. 

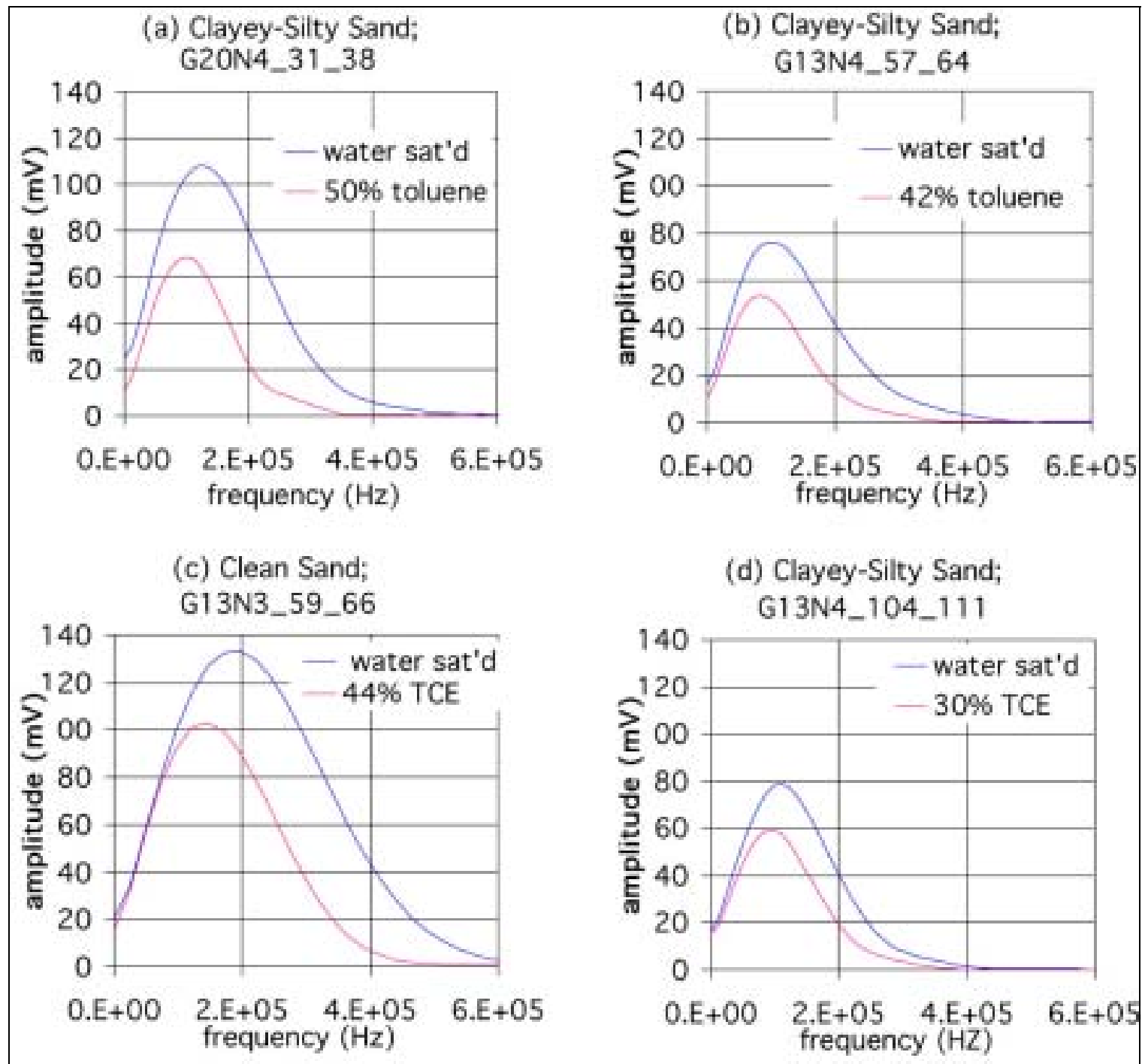

Figure 7.: Amplitude spectra for water-saturated samples and at maximum NAPL saturation.

In Figure 7, the amplitude spectra of the four samples for the water-saturated states are compared with the point of maximum NAPL saturation. The spectra of all samples show a decrease in peak frequency with the presence of NAPL. The spectra of the clayey-silty sands (Figures $7 \mathrm{a}, \mathrm{b}$ and $\mathrm{d}$ ) show a decrease in all frequencies, while that of the clean sand sample (Figure $7 \mathrm{c}$ ) only shows a change in frequencies greater than $70 \mathrm{kHz}$. Wavelengths at the central frequency for each sample range from $\sim 1$ to $2 \mathrm{~cm}$.

The attenuation coefficients were calculated from the ratio of each spectrum to that of the water standard [2], or

$$
\text { alpha }=\frac{1}{L} \ln \left(\frac{\hat{u}_{\text {water }}}{\hat{u}_{\text {sample }}}\right)
$$

where alpha is the attenuation coefficient, $L$ is the sample length and $\hat{u}$ is the spectrum for the water standard or sample, as denoted by the subscript. The results are plotted in Figure 8. 


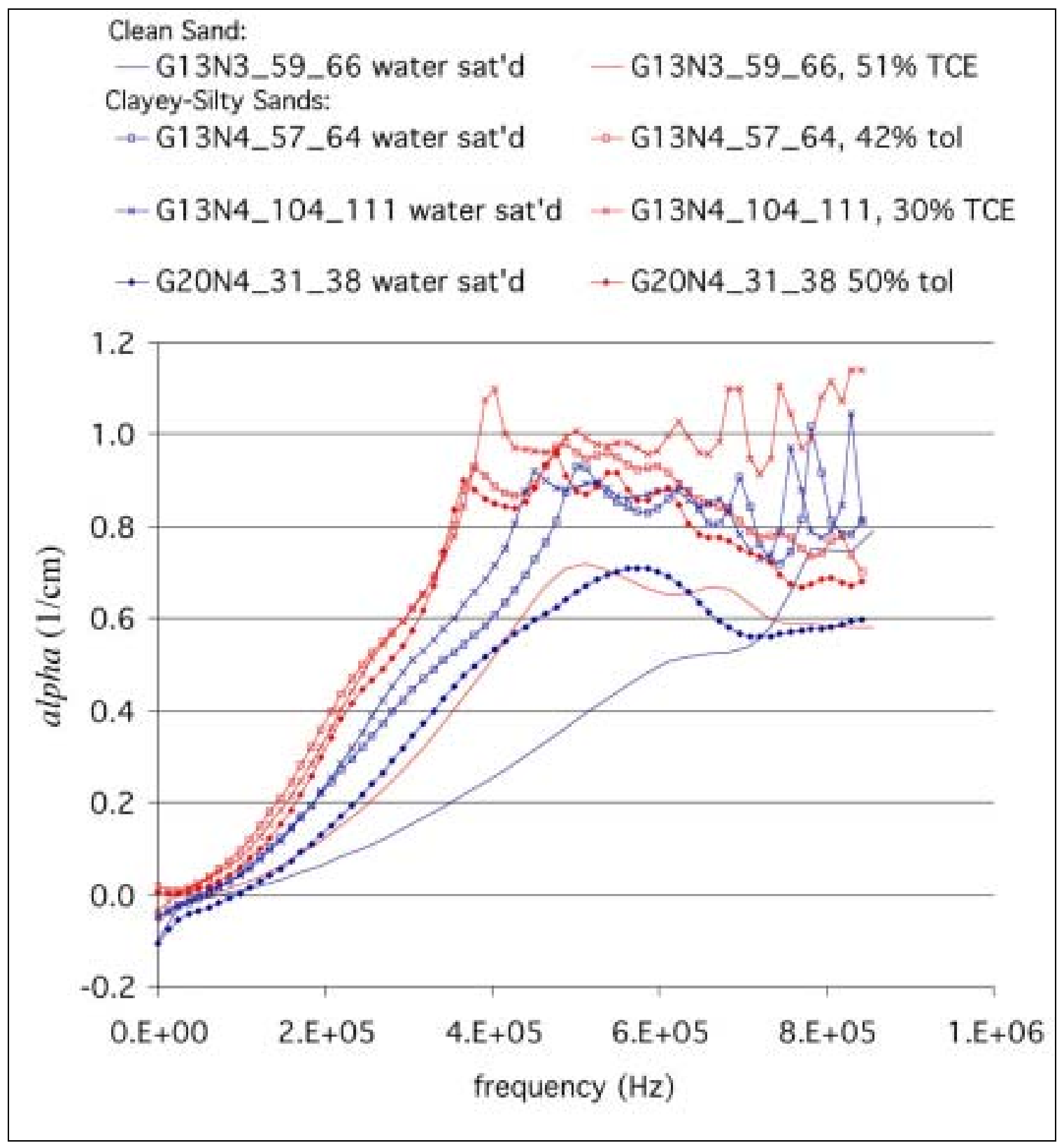

Figure 8.: Attenuation coefficients (alpha) from ratio of spectra of sample to water standard.

These plots provide usable attenuation data within the frequency range of about 100 to $400 \mathrm{kHz}$. Attenuation through the water-saturated samples (in blue) is much greater in the clayey-silty sands of the lower surficial aquifer $\left({ }^{*} \mathrm{n} 4 *\right)$, compared to the clean sand $(\mathrm{G} 13 \mathrm{n} 3 *)$. NAPL contamination in the clean sand results in attenuation that is more strongly frequency-dependent compared to that in the clayey-silty sands.

\section{Conclusions}

This paper describes our first measurements of P-wave transmission through natural aquifer samples as a function of NAPL saturation. P-wave transmission has been shown to be sensitive to the 
presence of immiscible liquid phases, however evaluation of the detectability of NAPLs by high frequency seismic tomography requires quantitative relationships that describe the effect of NAPL contaminants on P-wave transmission. While the number of samples tested to-date is too small to derive rock-physics models, the data provide direction for further testing.

P-wave velocities through water-saturated samples varied by about $4 \%$ due to differences in grain-size distributions. This variation is smaller than the velocity changes observed in the field (10$12 \%$ ), and smaller than the decrease of 5 to $9 \%$ in P-wave velocity reported here due to NAPL saturations of 30 to $50 \%$. Attenuation is more sensitive to both the changes in grain-size distribution (about a doubling in attenuation coefficients between water-saturated samples of different compositions) as well as to changes due to NAPL saturations (two to three times increase in attenuation coefficient).

To evaluate whether any of the attenuation effects measured in the lab can explain the attenuation anomalies observed in the field, it is important to understand the underlying attenuation mechanism and its frequency dependence. Liquid viscosity contrasts may contribute to pore-scale flowbased attenuation mechanisms. Energy scattering off of NAPL ganglia or patches may occur as the result of the acoustic impedance mismatch of the immiscible liquids. These factors will be considered in future tests, as well as the effect of a gas phase. The data here also suggest that the attenuation mechanism due to immiscible liquds may be sensitive to the grain texture and effective stress. We observed that in the clean sand sample, attenuation was sensitive to effective stress, and saw a frequency dependence that was not present in the clayey-silty sands.

\section{Acknowledgments}

This work was funded by the Subsurface Contamination Focus Area of the Environmental Management Program of the USDOE, under contract \#DE-AC-03-76F0098. We gratefully acknowledge the DOE Pinellas Site Manager, David Ingle, and his staff from S. M. Stoller Corporation, for support of our field work, and for sharing site characterization data. Members of the LBNL fielddata acquisition team were Cecil Hoffpauier, Kenneth Hurst Williams and Philip Rizzo. Liviu Tomutsu of LBNL acquired and processed the XRT data and provided advice regarding sample-handling

methods. Victor Gruol of LBNL provided apparatus design and fabrication support. We are grateful to Seiji Nakagawa of LBNL for consultations regarding experimental design and waveform processing, and to Kurt Nihei of LBNL for reviewing this paper.

\section{References}

1. Ajo-Franklin, J. B., J. T. Geller, E. L. Majer, J. E. Peterson, K. H. Williams and J. M. Harris (2003), "Preliminary geophysical characterization of a NAPL-contaminated site using borehole techniques", in this proceedings.

2. Bourbie, T.,O. Coussy. and B. Zinszner (1987), Acoustics of Porous Media, Gulf Publishing Co., Houston, TX, 334 pp.

3. Gee, G. W. and J. W. Bauder (1986), "Particle size analysis", in Methods of Soil Analysis, Part 1. Physical and Mineralogical Methods, Agronomy Monograph no. 9 ( $2^{\text {nd }}$ Edition), pp. 383-411, Madison, WI, American Society of Agronomy-Soil Science Society of America.

4. Geller, J. T. and L. R. Myer (1995), "Ultrasonic imaging of organic liquid contaminants in unconsolidated porous media”, Journal of Contaminant Hydrology, 19(3), pp. 85-104. 
5. Geller, J. T., M. B. Kowalsky, P. K. Seifert and K. T. Nihei (2000), “Acoustic Detection of Immiscible Liquids in Sand”, Geophysical Research Letters, 27(3), pp. 417-420.

6. Kowalsky, M. B., J. T. Geller, P. K. Seifert, K. T. Nihei, R. Gritto, J. E. Peterson, Jr. and L. R. Myer (1998), "Acoustic visibility of immiscible liquids in poorly consolidated sand," 1998 International Exposition and 68th Annual Convention, Society of Exploration Geophysics, New Orleans, LA.

7. U.S.D.O.E (2000a), Northeast Site NAPL Characterization Report, Document Number N0031600, Grand Junction, CO, October.

8. U.S.D.O.E. (2000b), Northeast Site NAPL Characterization Report Addendum, Document Number N0037300, Grand Junction, CO, October.

9. U.S.D.O.E. (1998), Cost and Performance Report - Dual Auger Rotary Steam Stripping, Pinellas Northeast Site, Largo, Florida, Innovative Treatment Remediation Demonstration, April. 